\title{
Simulation of Gas-Liquid Flow in Dripping Zone of Blast Furnace Involving Impermeable Fused Layers
}

\author{
G. X. WANG, J. D. LITSTER and A. B. YU'11 \\ Department of Chemical Engineering, University of Queensland, Brisbane, QLD 4072 Australia. \\ Email: gxwang@cheque.uq.edu.au. $\quad 1)$ School of Materials Science and Engineering, University of New South Wales, \\ Sydney, NSW 2052 Australia.
}

(Received on October 1, 1999; accepted in final form on March 6, 2000)

\begin{abstract}
A newly developed gas-liquid two-phase model has been employed to simulate the flow of gas and liquid in a blast furnace. This model accounts for the existence of impermeable fused layers in the blast furnace cohesive zone and treats the liquid as a discrete phase as revealed by experimental observation. The model has been run with a variety of assumed cohesive zones under a given blast furnace condition, giving the flow pattern and the distributions of liquid flow rates and liquid holdup. The results demonstrate the localized horizontal or upward flow characteristics of discrete liquid in and below the blast furnace cohesive zone. These characteristics are affected by the cohesive zone structure that can be described in terms of shape, position and the numbers of fused layers. The study reinforces the need to implement liquid flow in blast furnace modelling.
\end{abstract}

KEY WORDS: blast furnace; gas-liquid flow; discrete flow; numerical model; packed bed; cohesive zone.

\section{Introduction}

Counter-current gas and liquid flows in the lower part of a blast furnace, in particular the flow and re-distribution of liquid iron and slag generated in the cohesive zone $(\mathrm{CZ})$, play an important role in stable furnace operation. Furnace stability is very sensitive to changes of burden permeability, particularly under PCI (Pulverized Coal Injection) operation that has become a widely applied technology in blast furnace. Permeability has been identified as being closely related to the gas-liquid flow phenomena in the furnace lower part. ${ }^{1)}$ Thereby there is an increasing need to accurately predict the gas and liquid flow behavior for improving the blast furnace operation. Numerical simulation based on the theoretical and experimental models can provide a convenient way to tackle this problem.

Traditionally, liquid flow behavior in the blast furnace has been described using Darcy's equation in which the liquid is assumed to be a continuous phase. ${ }^{2,3)}$ As a result, early liquid models applied to the blast furnace were developed based on the potential or continuous approach. ${ }^{4,5)}$ Recently, Austin et al. ${ }^{6}$ ) reported a continuum-based model to simulate the multiphase flow in a blast furnace.

On the other hand, the discrete liquid flow has been elucidated by a number of experimental investigations concerning liquid flow in the blast furnace. ${ }^{7-10}$ ) This kind of liquid flow is usually featured with a so-called free boundary, i.e. the flow region is not defined during liquid flow. ${ }^{11,12)}$ To simulate this flow behavior, Wang et al. ${ }^{13)} \mathrm{de}-$ veloped a combined probability-continuous model, while Eto et al. $^{14)}$ proposed a so-called Dynamic Model with a tube network.

However it is difficult to apply the above models under actual flow conditions due to disadvantages in either concept or numerical technique. ${ }^{15)}$ To fill this gap, an alternative model has been developed based on discrete flow considerations. ${ }^{15}$ ) This model has been successfully applied to simulate gas-liquid flow in both uniform and non-uniform packed beds. Packed beds with both simple geometry and multi-layered structure were used. The latter was mainly designed to evaluate the usability of the model under more realistic blast furnace conditions. The validity of this model has been demonstrated by the reasonable agreement between the model predictions and measurements obtained using various cold model apparatuses under different gas and liquid flow conditions. ${ }^{15,16)}$

Extensive dissection studies of blast furnaces demonstrate the existence of impermeable fused layers in the CZ. ${ }^{17)}$ These fused layers are the source of the liquid iron and slag generated as ore and other iron-bearing burdens are reduced and melt. The distribution of these fused layers depends on temperature fields and composition of the gas and solid in the blast furnace and significantly affects the flow of gas and liquid, giving different $\mathrm{CZ}$ structures, e.g. inverse V-, W- and V-shaped. The flows in turn control the heat and mass transfer in the blast furnace, and hence the temperature fields and the $\mathrm{CZ}$ structure. The interrelationship between the $\mathrm{CZ}$ structure and the gas-liquid flow forms a critical controlling factor that maintains the stability of blast furnace operation. Therefore it is important to take into account the existence of the impermeable fused layers in blast furnace models, particularly in liquid flow 
models. Such a model does not appear to have been well developed.

The current work extends the newly developed model, as mentioned above, to blast furnace condition involving a number of impermeable fused layers. An industrial scale blast furnace was used to provide relevant information such as the geometry and other input parameters for the simulation. The focus of this study is the investigation of the impact of $\mathrm{CZ}$ structure and the interaction between gas and liquid flows in a blast furnace. The flow pattern and the distributions of liquid flow rates and liquid holdup under various CZs will be analyzed. The results show the localized horizontal and upward flow characteristics of the discrete liquid through the blast furnace packed bed. These characteristics are affected by the $\mathrm{CZ}$ structure that can be described in terms of shape, position and the number of fused layers.

\section{Model Description}

The Ergun-type equation has been widely used to model gas flow in a packed bed and proved to be adequate for blast furnace gas flow modelling. Under the gas-liquid twophase flow condition, the equations of continuity and momentum for steady-state gas flow can be given by:

$$
\operatorname{div}\left\{\rho_{\mathrm{g}} \varepsilon_{\mathrm{g}} \vec{V}_{\mathrm{g}}\right\}=0
$$

and

$$
-\varepsilon_{\mathrm{g}} \operatorname{grad}(P)=\vec{F}_{\mathrm{g}}^{\mathrm{b}}+\vec{F}_{\mathrm{g}}^{1}
$$

where $\varepsilon_{\mathrm{g}}, \rho_{\mathrm{g}}, P$ and $\vec{V}_{\mathrm{g}}$ are the volume fraction of gas in packed beds, gas density, gas pressure and the interstitial velocity of gas, respectively. $\vec{F}_{\mathrm{g}}^{\mathrm{b}}$ is the bed resistance force on gas flow, which can be determined by:

$$
\begin{aligned}
\vec{F}_{\mathrm{g}}^{\mathrm{b}}= & 150.0 \mu_{\mathrm{g}}\left[\frac{1-\varepsilon_{\mathrm{g}}}{\left(1-\varepsilon_{\mathrm{p}}-\varepsilon_{1}\right) \psi_{\mathrm{p}} d_{\mathrm{p}}}\right]^{2}\left(\frac{\vec{V}_{\mathrm{g}}}{\varepsilon_{\mathrm{g}}}\right)^{2} \\
& +1.75 \rho_{\mathrm{g}}\left[\frac{1-\varepsilon_{\mathrm{g}}}{\left(1-\varepsilon_{\mathrm{p}}-\varepsilon_{1}\right) \psi_{\mathrm{p}} d_{\mathrm{d}}}\right]\left(\frac{1}{\varepsilon_{\mathrm{g}}}\right)^{2}\left|\vec{V}_{\mathrm{g}}\right| \vec{V}_{\mathrm{g}} \ldots \ldots
\end{aligned}
$$

and $\vec{F}_{\mathrm{g}}^{1}$ is interaction of liquid flow on gas flow, which can be determined through the calculation of the gas drag force acting on liquid, $\vec{F}_{1}^{\mathrm{g}}$ (i.e. $\vec{F}_{\mathrm{g}}^{1}=-\vec{F}_{1}^{\mathrm{g}}$ ), as shown later (see Eq. (3a)). $\mu_{\mathrm{g}}$ is the gas viscosity, and $\psi_{\mathrm{p}}$ and $d_{\mathrm{p}}$ are the shape coefficient and diameter of particles, respectively. $\varepsilon_{\mathrm{p}}$ and $\varepsilon_{1}$ are respectively the volume fractions of particles and liquid and has a relation expressed as $\varepsilon_{\mathrm{g}}+\varepsilon_{1}+\varepsilon_{\mathrm{p}}=1$, where $\varepsilon_{1}$ is equal to the total holdup of liquid that can be estimated using relevant formulae from the literature. ${ }^{4,15)}$ Note that this gas model is similar to earlier models ${ }^{4-6,13,14)}$ due to the continuous assumption for the gas flow, but includes the interaction between gas and the discrete liquid.

The proposed liquid flow model is composed of a liquid flow sub-model which features the force balance applied to discrete liquid flow and a liquid dispersion sub-model to consider the stochastic motion that relates to the complex packing geometry. ${ }^{15)}$ The main features of the two submodels are described as follows.

\section{- Liquid Flow Sub-model}

The behaviour of discrete liquid flow through packed particles is principally governed by three forces: the gas drag force $\vec{F}_{1}^{\mathrm{g}}$, the bed resistance force $\vec{F}_{1}^{\mathrm{g}}$ and gravity $\vec{F}_{\mathrm{g}}$ $\left(=\varepsilon_{1} \rho_{1} \vec{g}\right)$. According to the force balance approach, ${ }^{7,15)}$ liquid quickly establishes a uniform macroscopically percolation velocity through a packed bed, despite possible local acceleration or deceleration at the scale of individual particles. Hence the three forces are balanced under a macroscopically steady-state condition, i.e.:

$$
\vec{F}_{1}^{\mathrm{g}}+\vec{F}_{1}^{\mathrm{b}}+\varepsilon_{1} \rho_{1} \vec{g}=0
$$

where $\vec{F}_{1}^{\mathrm{g}}$ and $\vec{F}_{1}^{\mathrm{b}}$ are the gas drag force and the bed resistance force acting on liquid flow, respectively. In this model, these forces are written in the form

$$
\vec{F}_{1}^{\mathrm{g}}=\phi_{1} \varepsilon_{1} \rho_{\mathrm{g}}\left|\vec{V}_{\mathrm{g}}-\vec{V}_{1}\right|\left(\vec{V}_{\mathrm{g}}-\vec{V}_{1}\right)
$$

and

$$
\vec{F}_{1}^{\mathrm{b}}=\phi_{2} \varepsilon_{1} \rho_{1}\left|\vec{V}_{1}\right| \vec{V}_{1}
$$

The model parameters $\phi_{1}$ and $\phi_{2}$, representing the interactions between gas and liquid, and packed bed and liquid, respectively, are determined by:

$$
\phi_{1}=\frac{C_{\mathrm{DG}} A_{\mathrm{g}-1}}{2 \varepsilon_{1}}
$$

and

$$
\phi_{2}=\frac{C_{\mathrm{DS}} A_{\mathrm{s}-1}}{2 \varepsilon_{1}}
$$

where $\rho_{1}$ and $\vec{V}_{1}$ are the density and interstitial velocity (major stream) of the liquid. $C_{\mathrm{DG}}$ and $C_{\mathrm{DS}}$ are the gas drag coefficient and bed drag coefficient, respectively; and $A_{\mathrm{g}-1}$ and $A_{\mathrm{s}-1}$ are the effective contact areas between liquid and gas, and liquid and solid, respectively. For a given flow system, $\phi_{1}$ and $\phi_{2}$ can be determined by the technique suggested elsewhere. ${ }^{18)}$

\section{- Liquid Dispersion Sub-model}

An important feature of the flow of liquid through a packed bed is its dispersion in a certain flow region, resulting in a stochastic contribution to the major stream. It can be seen that Eq. (3) permits the determination of the velocity and direction of the major stream for the liquid flow, but makes no allowance for the stochastic contribution. The liquid dispersion sub-model can be effected by adding a stochastic velocity to any liquid point, and hence permits the calculation of the stochastic contribution to any major stream. ${ }^{15)}$. In the liquid dispersion sub-model, the stochastic contribution of the liquid dispersion to the major stream is calculated by means of a probability fraction, using the stochastic velocity distribution relative to the major stream. The probability fraction is then used to determine the liquid flow region and the distribution of liquid flow rates in the given region, giving a general mass balance equation as follows:

$$
\begin{aligned}
& F_{i, j}=p_{i-1, j, 1} F_{i-1, j}+p_{i-1, j-1,2} F_{i-1, j-1}+p_{i, j-1,3} F_{i, j-1} \\
& +p_{i+1, j-1,4} F_{i+1, j-1}+p_{i+1, j, 5} F_{i+1, j}+p_{i+1, j+1,6} F_{i+1, j+1} \\
& +p_{i, j+1,7} F_{i, j+1}+p_{i-1, j+1,8} F_{i-1, j+1}
\end{aligned}
$$




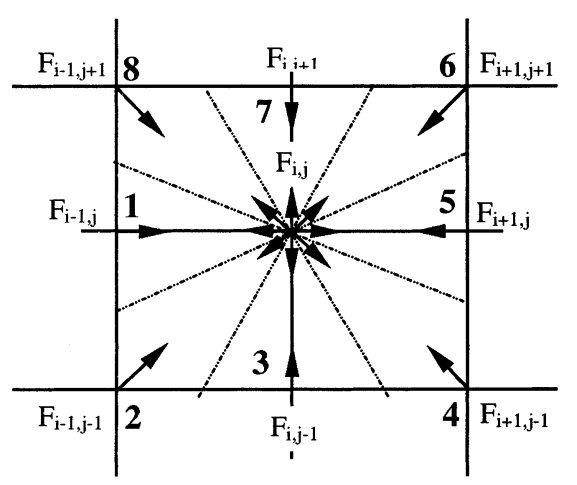

Fig. 1. The discrete liquid flow in a control volume.

This equation is derived from a selected control volume that includes 9 discrete points numbered as illustrated in Fig. 1, where $F$ represents the flow rate passed by the discrete points and $p$ is defined as the probability fraction of the discrete liquid flowing from the given point to its neighboring points. The value of $p$ can be calculated by the liquid dispersion sub-model, in which the velocity (major stream) and stochastic movement of liquid flow in a packed bed were simultaneously considered. ${ }^{15}$ Treatments of liquid flow at boundary can be found elsewhere. ${ }^{16)}$

It should be pointed out that while the principles outlined above are generally valid, different grid configurations for numerical computation may give different expressions for the mass balance. Equation (4) is only for a square grid configuration which is not effective if the liquid dispersion is small. As shown in Fig. 1, if the maximum dispersion angle, corresponding to the maximum stochastic velocity. ${ }^{15,16)}$ is less than 22.5 degree, liquid dispersion will be ignored by this method. In principle, the liquid flow model proposed is suitable for either pig-iron or liquid slag. However, as implied in Eq. (3), liquid slag is more sensitive to the gas drag force in the blast furnace because of its lower density. Therefore, the current study will only focus on the simulation of liquid slag flow in a blast furnace which is more dispersed than liquid iron.

\section{Simulation Conditions}

\subsection{The CZ Geometry}

The geometric parameters used for simulation are from an actual blast furnace that has an inner volume of $\sim 1300 \mathrm{~m}^{3}$ with hearth diameter of $7.2 \mathrm{~m}$ and height of $33 \mathrm{~m}$. This furnace is operated with full coke and a burden comprising sinter $(70 \%$ of the burden), lump ore (15 to $20 \%$ ) and pellets (10 to $15 \%$ ). During its present campaign, the average productivity coefficient is $\sim 2.0 \mathrm{t} / \mathrm{m}^{3} \cdot \mathrm{d}$ and slag rate is less than $400 \mathrm{~kg} / \mathrm{tHM}$.

Figure 2 illustrates the geometry of the blast furnace with a cylindrical coordinate system in which the origin point is set at the level of the tuyeres. The burden surface used for simulation is assumed based on burden distribution at the throat. For the convenience of discussion, the $\mathrm{CZ}$ definition has been indicated with various parameters such as root radius and height, $\mathrm{CZ}$ width, incline angles, etc. In accordance with the actual blast furnace, the cohesive layers are regarded as impermeable in the simulation.

In order to investigate the effect of the $\mathrm{CZ}$ structure on

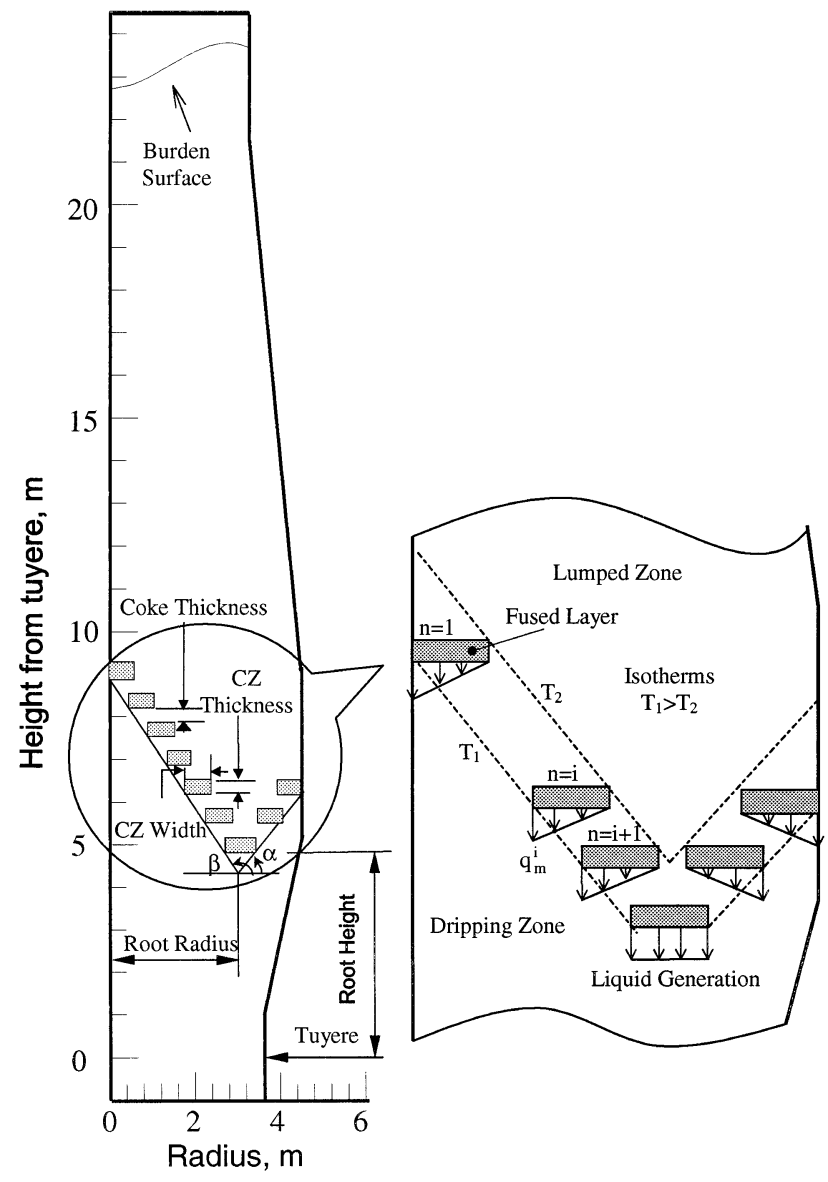

Fig. 2. Dimensions of blast furnace and definition of $\mathrm{CZ}$ parameters for simulation.

Table 1. Cases designed for simulation of liquid flow in a blast furnace.

\begin{tabular}{|c|c|c|c|c|c|c|c|}
\hline \multirow{2}{*}{$\begin{array}{c}\text { Cohesive } \\
\text { zone } \\
\text { (case) }\end{array}$} & \multirow{2}{*}{$\begin{array}{c}\text { Root } \\
\text { height } \\
\text { (m) }\end{array}$} & \multirow{2}{*}{$\begin{array}{c}\text { Root } \\
\text { radius } \\
(\mathrm{m})\end{array}$} & \multirow{2}{*}{$\begin{array}{c}\text { Incline } \\
\alpha \\
(\mathrm{deg})\end{array}$} & \multirow{2}{*}{$\begin{array}{c}\text { angle } \\
\beta \\
(\mathrm{deg})\end{array}$} & \multicolumn{2}{|c|}{$\mathrm{CZ}$ layer } & \multirow{2}{*}{$\begin{array}{l}\text { Ratio of } \\
\text { ore/coke } \\
\text { thickness }\end{array}$} \\
\hline & & & & & $\begin{array}{c}\text { Width } \\
\text { (m) }\end{array}$ & $\begin{array}{c}\text { Number } \\
n_{\Sigma}\end{array}$ & \\
\hline \multicolumn{8}{|c|}{ Inverse V-shaped } \\
\hline Base A & 3.375 & 3.825 & - & 124 & 0.675 & 9 & 1.0 \\
\hline Case -1 & $1.575^{*}$ & $\underline{3.600}$ & - & 124 & 0.675 & 9 & 1.0 \\
\hline Case -2 & 3.375 & 3.825 & - & 124 & $\underline{0.450}$ & 9 & 1.0 \\
\hline Case - 3 & 3.375 & 3.825 & - & $\underline{135}$ & 0.675 & 9 & 1.0 \\
\hline Case - 4 & 3.375 & 3.825 & - & 124 & 0.675 & $\underline{13}$ & 1.0 \\
\hline Case -5 & 3.375 & 3.825 & - & 124 & 0.675 & 9 & $\underline{2.0}$ \\
\hline \multicolumn{8}{|l|}{ W-shaped } \\
\hline Base B & 4.725 & 3.038 & 45 & 124 & 0.675 & 9 & 1.0 \\
\hline Case -6 & $\underline{2.475}$ & 3.038 & 45 & 124 & 0.675 & $\underline{8}$ & 1.0 \\
\hline Case -7 & 4.725 & 3.038 & 45 & 124 & $\underline{0.450}$ & 9 & 1.0 \\
\hline Case -8 & 4.725 & 3.038 & 45 & $\underline{135}$ & $\overline{0.675}$ & 7 & 1.0 \\
\hline Case - 9 & 4.725 & $\underline{2.138}$ & 45 & $\underline{135}$ & 0.675 & $\underline{8}$ & 1.0 \\
\hline Case - 10 & 4.725 & 3.038 & 45 & 124 & 0.675 & 9 & $\underline{2.0}$ \\
\hline \multicolumn{8}{|l|}{ V-shaped } \\
\hline Base C & 3.375 & 0.225 & 56 & - & 0.675 & 9 & 1.0 \\
\hline
\end{tabular}

* $\underline{x x}$ means the changed parameter(s) compared with the corresponding base.

the gas and liquid, three typical CZs, i.e. inverse V-, W- and $\mathrm{V}$-shaped are employed in this study. For a specified CZ, the $\mathrm{CZ}$ parameters are dependent on the furnace operating conditions such as ore-to-coke ratio, softening/melting rate, fuel consumption and temperature distribution in the furnace. The parameters for various cases used in this work are detailed in Table 1.

\subsection{Liquid Generation}

The majority of the liquids in the blast furnace, both pigiron and slag are produced in the $\mathrm{CZ}$ zone. Liquids generated on the underside of the $\mathrm{CZ}$ layers are here defined as the 
initial liquid sources, which provides the model with initial conditions. It appears difficult to determine the source term for any given $\mathrm{CZ}$ layer using either existing theory or measurement. However it is possible to estimate the initial liquid sources based on the productivity of the actual blast furnace and the number of $\mathrm{CZ}$ layers involved. Within the given $\mathrm{CZ}$, liquid pig-iron and slag begin to form and drop down from the ore layers. The current work does not cover heat transfer and chemical reactions in the blast furnace. Therefore the liquid generation is approximately estimated based on the following assumptions.

1) The solid temperature profile defining the $\mathrm{CZ}$ in the blast furnace can be represented with straight or stacked isotherms $T_{1}$ and $T_{2}$, as shown in Fig. 2. Both inner and outside boundaries of the $\mathrm{CZ}$ are approximately matched with the temperature profile.

2) The gas has a similar temperature profile to the solid within the $\mathrm{CZ}$. The temperature gradients of the gas and the solid are linearly varied within the $\mathrm{CZ}$.

3) Each CZ layer has a uniform thickness and width, thus there are the same number of liquid-generating points for each CZ layer.

4) The liquid flow rates from the liquid-generating points are proportional to the reduction degree of the ore or iron-bearing burden, being dependent on the temperature only.

Figure 2 also indicates a schematic liquid generation for each $\mathrm{CZ}$ layer according to the above assumptions. As a result, except for the root layer of the W-shaped CZ, the total liquid generation from each layer is uniform. In the case where a $\mathrm{W}$-shaped $\mathrm{CZ}$ is formed, the layer on the $\mathrm{CZ}$ root will generate twice the liquid compared with other $\mathrm{CZ}$ layers. This presumed result appears consistent with the liquid flow phenomena in a blast furnace reported by Sawa et $a l .{ }^{19,20)}$

Thus, a general mathematical formulation can be obtained to determine the initial flow rate of liquid (slag) at the $m$-th point of the $i$-th layer. That is:

$$
\begin{aligned}
& q_{m}^{i}= \\
& \begin{cases}\frac{Q_{\Sigma}}{n_{\Sigma}+a_{0}} \frac{m}{\sum_{T=1}^{m_{0}} T} & \text { (excluding the root layer of W - shaped CZ) } \\
\frac{Q_{\Sigma}}{n_{\Sigma}+a_{0}} \frac{1}{m_{0}} & \text { (only the root layer of W - shaped CZ) }\end{cases}
\end{aligned}
$$

where $a_{0}$ is equal to 1 for the $\mathrm{W}$-shaped CZ, otherwise 0 . Superscript $i$ means the $i$-th layer and subscript $m$ $\left(m=1,2, \ldots, m_{0}\right)$ is the number of points in which liquid can be generated, ordered from the $\mathrm{CZ}$ outside (corresponding to the side with lower temperature in $\mathrm{CZ}$ ) to inner (with higher temperature). $n_{\Sigma}$ and $Q_{\Sigma}$ are total number of the $\mathrm{CZ}$ layers and total flow rate of liquid (slag) formed by the whole $\mathrm{CZ}$, respectively.

\subsection{Solution Method}

A coupled solution technique, consisting of numerical computation of the gas flow field and liquid flow field, was developed. Simulation of the gas flow field can be achieved using a well-established numerical method, e.g. the stream function, which provides the gas velocity distribution necessary for calculation of the liquid flow model. Simulation of the liquid flow can be achieved by use of the numerical technique suggested by Wang et al. ${ }^{15,16)}$ The technique utilises the liquid velocity vector, determined by the force balance approach, and the stochastic velocity, given by the stochastic treatment, to determine the liquid flow dispersion angle and probability distribution for liquid flowing towards neighbouring nodes, starting from liquid sources. Subsequently, combining the given probability distributions of stochastic velocity and flow rates of liquid sources, a set of linear equations in terms of all nodal liquid flow rates in the flow region can be established according to the mass balance principle, as shown in Eq. (4). Their numerical solution gives the liquid flow rate distribution in the coke bed in the dripping zone and, further, permits the determination of the liquid holdup distribution for a given gas flow field. The latter result can then be used to determine a new gas flow field according to the gas flow model mentioned above, which in turn leads to the determination of new liquid flow rate and holdup distributions. Coupling between gas and liquid flows can be effectively achieved by repeating the computation until both gas and liquid flow fields converge.

Equation (4) describes the relationship among the flow rates for a given control volume in the region where liquid flow occurs. Obviously, the main matrix of the linear equations given by Eq. (4) is indefinite, depending on the actual liquid flow region which can be determined by the liquid dispersion sub-model, as mentioned above. Once the flow region is worked out, the matrix becomes definite and the conjugate gradient method ${ }^{21)}$ is applied to the numerical solution of the equations. For application in blast furnaces, however, the size of the matrix that represents the number of solution sets is usually enormous. Solving such sets of simultaneous linear equations will take a long time. To make the model more efficient, a special program is used to reduce the set of linear equations and computing time. This program is designed only for the liquid flow model by which the lower part of the blast furnace is divided into two sections by the median between the bottom of the root $\mathrm{CZ}$ layer and the tuyere level. Assume that there is no liquidliquid interaction on this median, and hence mass continuity is applied. The same algorithms such as determination of liquid flow region and solution of the simultaneous linear equations are processed from upper to lower sections, and this gives the distribution of the liquid flow rates in whole liquid flow region for a given gas flow field.

A square grid of 220 axial and 40 radial divisions was employed for all calculations. The computer code is written in FORTRAN 90 and runs on a Pentium II personal computer. The simulation for a complete case involved in the current work takes about $30 \mathrm{~min}$.

\section{Results and Discussion}

The blast furnace data required for the simulation include the properties of burden bed, total rate and properties of liquid slag, and blast parameters in tuyere. The values are listed in Table 2. The model parameters $\phi_{1}$ and $\phi_{2}$ involved in the Eqs. (3a) and (3b), are the same as those used in previ- 
ous studies on liquid flow. ${ }^{14,15)}$

Figures 3 and 4 show the velocity vectors of gas and major liquid stream in the blast furnace involving three typ-

Table 2. Operating data of blast furnace used for the model.

\begin{tabular}{ll}
\hline Particle size $\mathrm{d}_{\mathrm{p}}, \mathrm{m}$ & 0.03 (ore) \\
& 0.05 (coke) \\
Shape factor $\psi,(-)$ & 0.75 \\
Bed porosity $\varepsilon_{\mathrm{p}},(-)$ & 0.40 \\
Gas flow rate entering a tuyere $\mathrm{Q}_{\mathrm{g}}, \mathrm{m}^{3} / \mathrm{h}$ & 115 \\
Gas viscosity $\mu_{\mathrm{g}}, \mathrm{Pa} \cdot \mathrm{s}$ & $1.987 \times 10^{-4}$ \\
Gas density $\rho_{\mathrm{g}}, \mathrm{kg} / \mathrm{m}^{3}$ & 1.17 \\
Productivity coefficient $\eta, \mathrm{t} / \mathrm{m}^{3} \cdot \mathrm{d}$ & 2.0 \\
Slag rate $\mathrm{Q}_{\mathrm{s}}, \mathrm{t} / \mathrm{d}$ & 1036 \\
Equivalent liquid flow rate $\mathrm{Q}_{\Sigma}, \mathrm{m}^{3} / \mathrm{h}$ & 9.0 \\
Slag viscosity $\mu_{\mathrm{l}}, \mathrm{Pa} \mathrm{s}$ & 0.01 \\
Slag density $\rho_{\mathrm{l}}, \mathrm{kg} / \mathrm{m}^{3}$ & 2600 \\
\hline
\end{tabular}

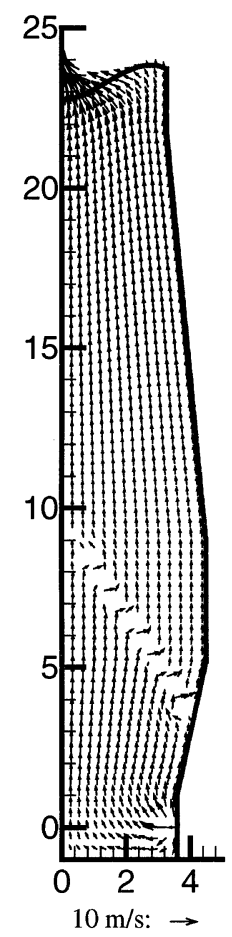

a) Base $A$

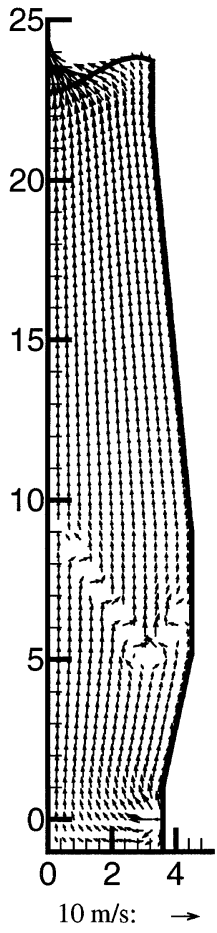

b) Base B

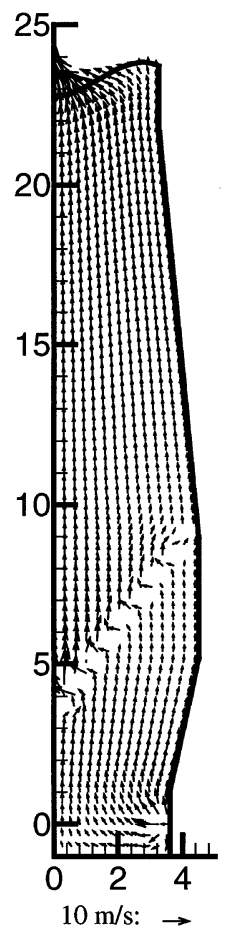

c) Base C
Fig. 3. Gas velocity vector with three typical $\mathrm{CZs}$ for the base cases. ical CZs for the base cases in this study, respectively. Under the given gas flow conditions, the liquid flow rate contours and total holdup distribution are correspondingly shown in Figs. 5 and 6.

The model is further employed to investigate the influence of the physical structure of the $\mathrm{CZ}$ on liquid flow. Typical results are illustrated in Figs. 7 to 11.

\subsection{Localized Liquid Flow in Blast Furnace}

Simulation in this study demonstrates that, for liquid slag, localized non-downward flow in the blast furnace is possible. It can be seen from Fig. 3 that strong cross flow occurs in the $\mathrm{CZ}$, due to impermeable layers, and in front of raceway because of the horizontal entry of blast air from the tuyere. This feature of the gas flow is the most important factor that determines the localized flow of liquid slag in blast furnace.

Associated with the gas flow, strongly localized liquid flow takes place in the $\mathrm{CZ}$ and raceway, featured by horizontal and upward flows as shown in Fig. 4. This phenomenon has been clearly demonstrated in the model experiments of Chew et al. ${ }^{9)}$ It is noteworthy that Fig. 4 only indicates the velocity vector of the major liquid stream. As implied in development of the liquid model, this vector reflects only the flow direction of the major liquid stream, rather than the flow rate. This is because momentum transfer for the discrete phase during its motion in packed beds is usually controlled by both the gas flow and the stochastic characteristics of liquid flow in packed beds, under a steady-state isothermal condition. As a result, the simulation using the current model indicates there are great differences from ones obtained by other approaches, e.g. Austin et al.'s liquid modeling. ${ }^{6,22)}$ One of the most important differences is that the current model directly calculates the distribution of liquid flow rates, rather than only the liquid velocity vectors. The former is of significance to blast furnace operators because it is consistent with change of the burden permeability in blast furnace lower zone.

Figure 5 gives three patterns of liquid flow in the blast furnace with respect to three typical $\mathrm{CZs}$, indicating that the distribution of liquid flow rates is obviously non-uniform in the blast furnace. In particular, corresponding to the initial liquid sources, there exist a series of "ice-bar" flows
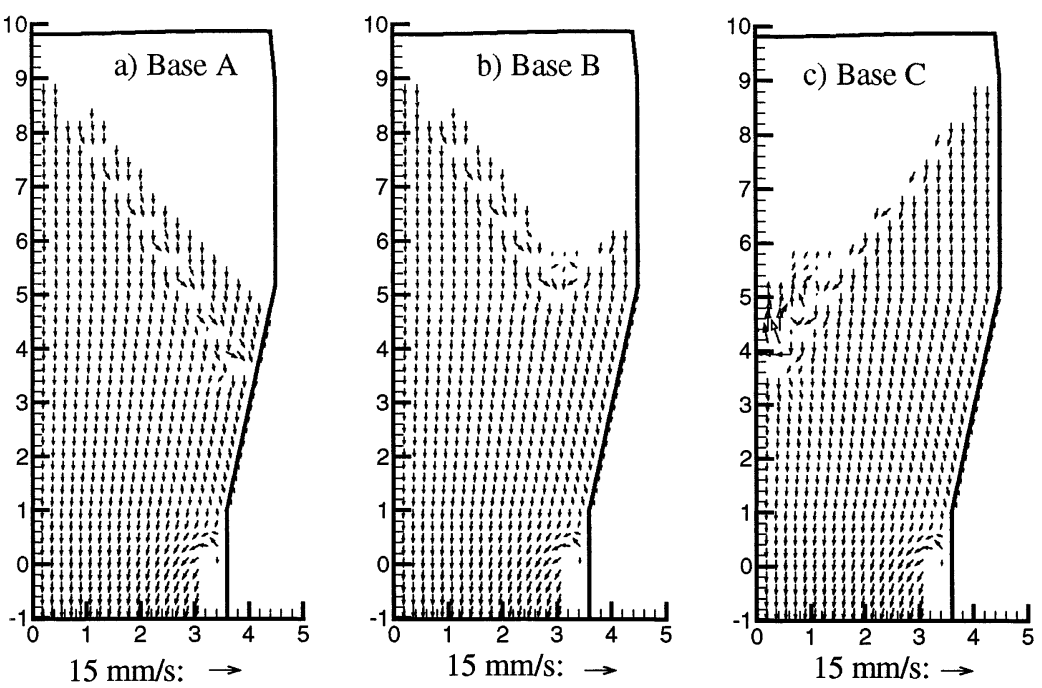

Fig. 4. Liquid velocity (main stream) vector with three typical $\mathrm{CZs}$ for the base cases. 

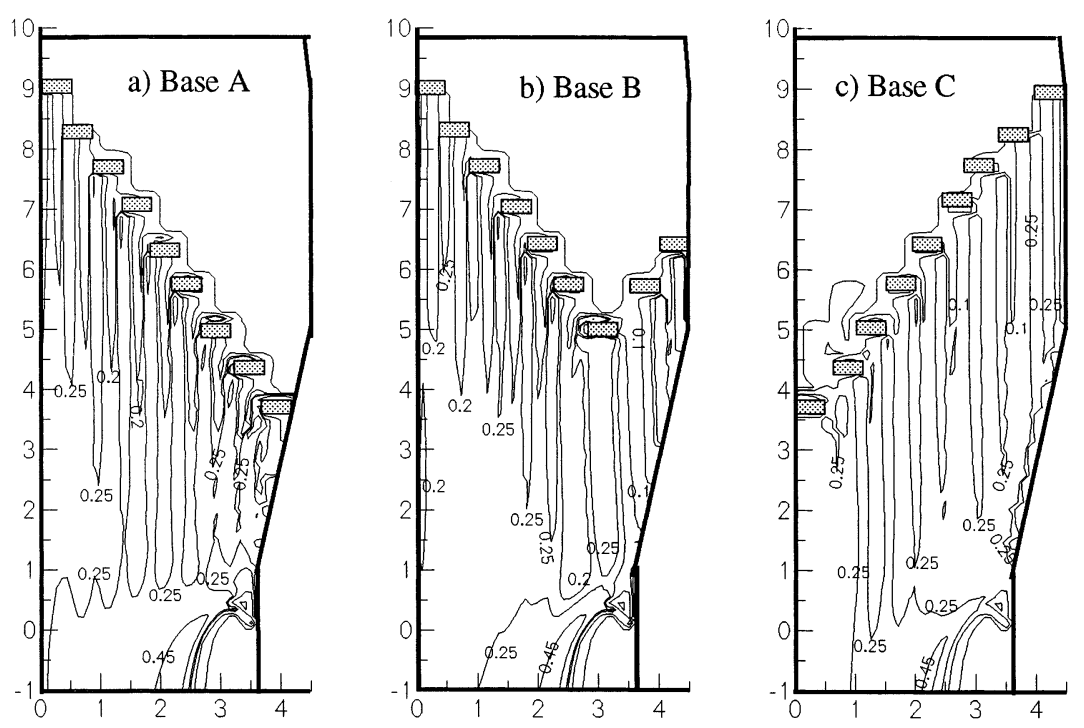

Fig. 5. Liquid flow patterns under the different $\mathrm{CZs}$ for the base cases (unit: $\mathrm{m}^{3} / \mathrm{h}$ ).
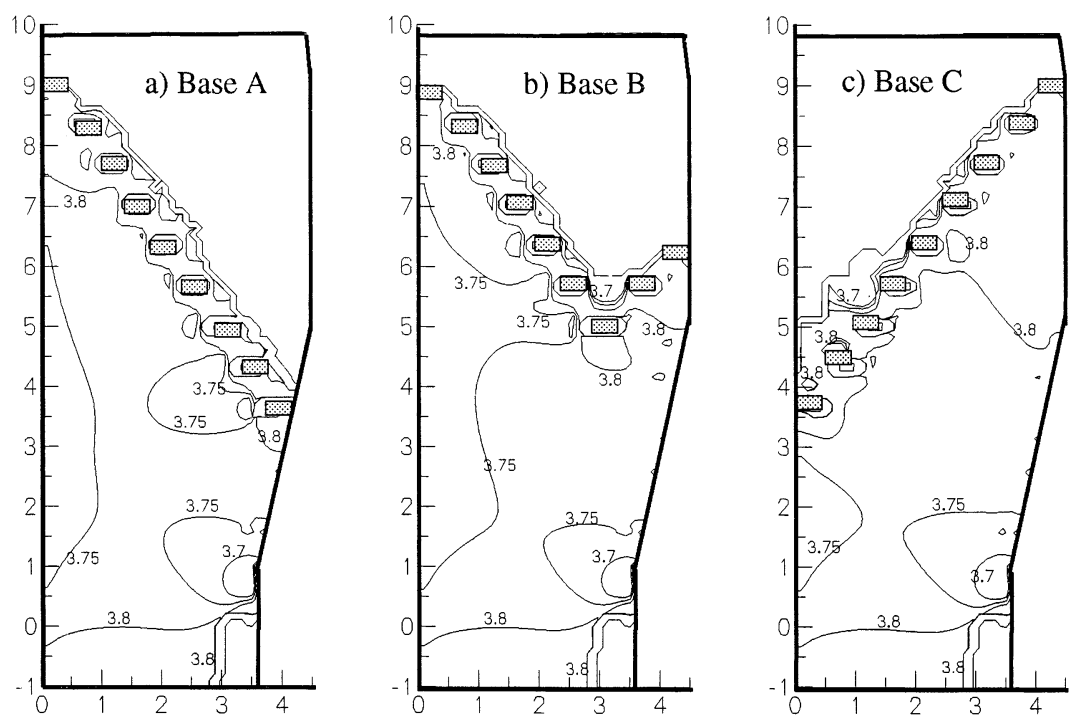

Fig. 6. Typical liquid holdup (total) distribution in a blast furnace (unit: vol\%).
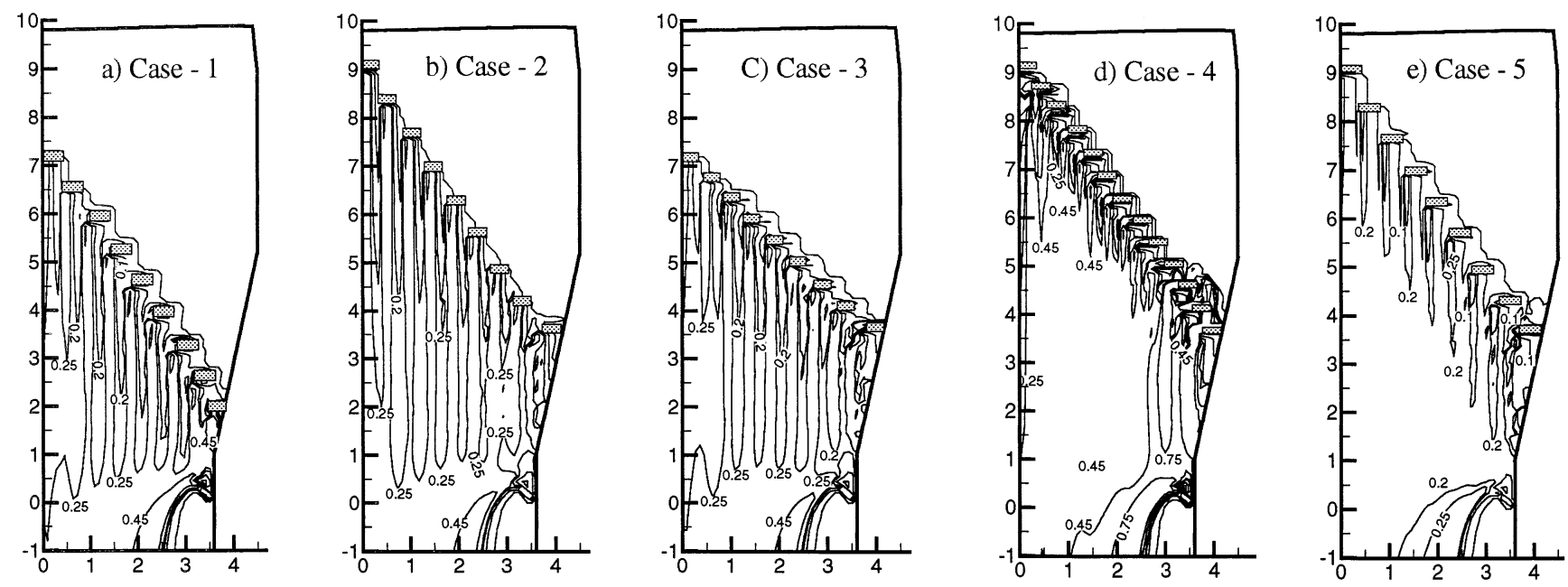

Fig. 7. Liquid flow in blast furnace under various inverse V-shaped CZs (unit: $\mathrm{m}^{3} / \mathrm{h}$ ).

with relatively high flow rates in the region near the $\mathrm{CZ}$, and the liquid flow near the raceway is strongly shifted by gas flow and then re-distributed in the lower zone, which re- sult in much more liquid flowing towards the $\mathrm{CZ}$ root. And secondly, the above characteristic can also be illustrated in terms of total liquid holdup distribution, i.e. the sum of stat- 

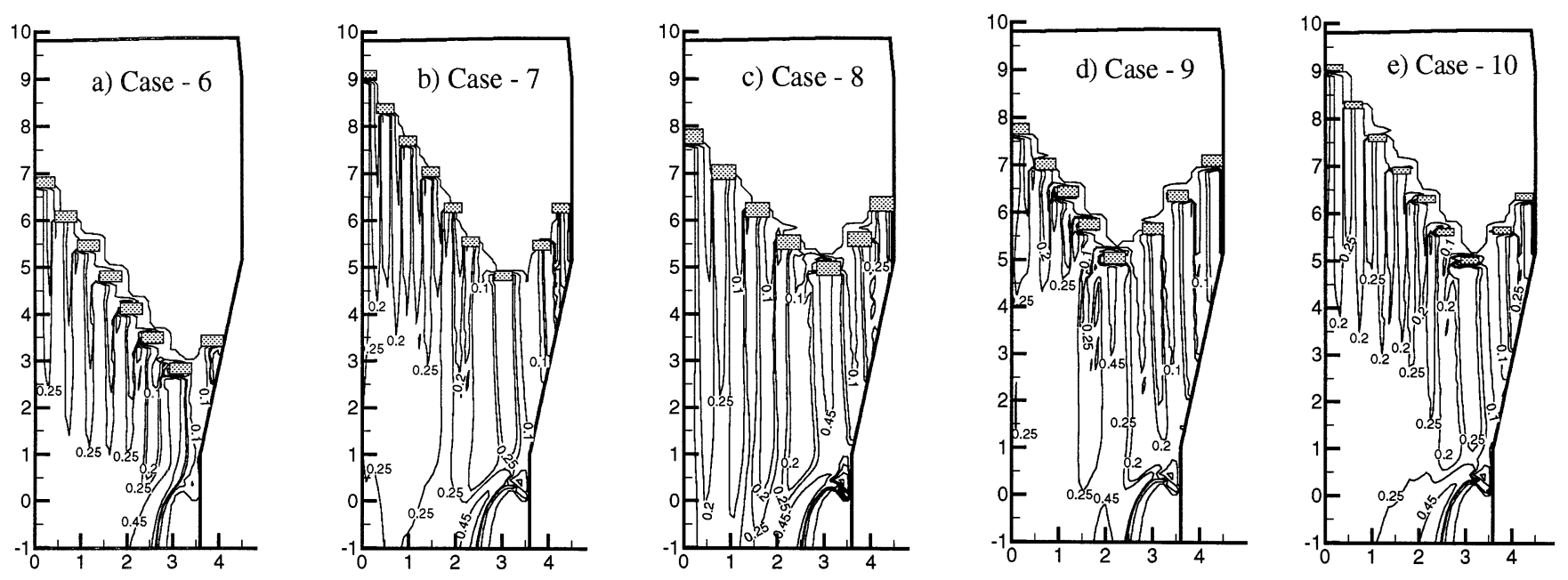

Fig. 8. Liquid flow in blast furnace under various W-shaped CZs (unit: $\mathrm{m}^{3} / \mathrm{h}$ ).
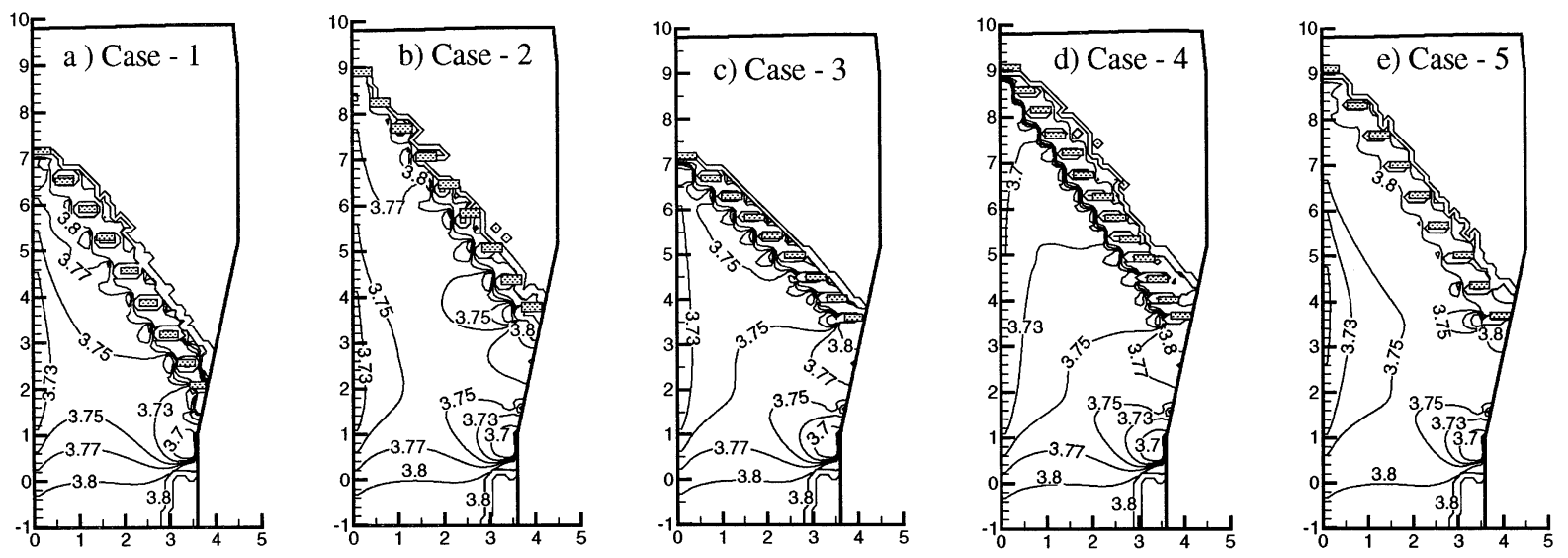

Fig. 9. Distribution of total liquid holdup under various inverse V-shaped CZs (unit: vol\%).
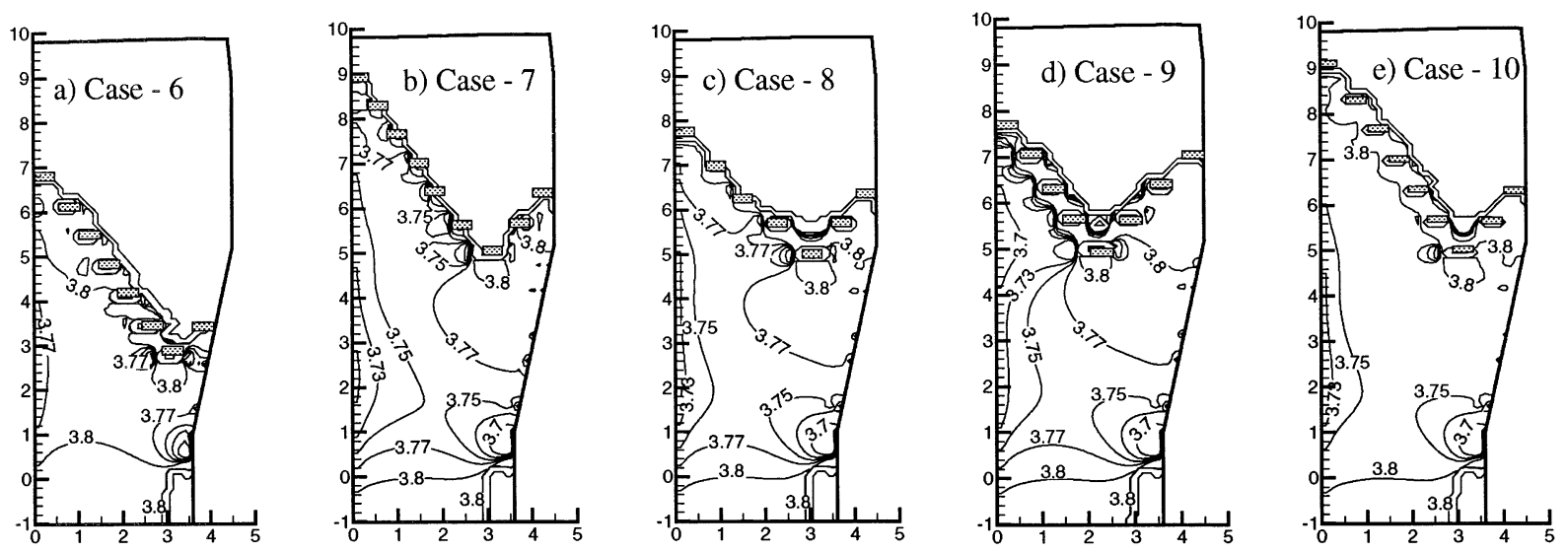

Fig. 10. Distribution of total liquid holdup under various $\mathrm{W}$-shaped $\mathrm{CZs}$ (unit: vol\%).

ic and dynamic holdups, as shown in Fig. 6.

The results suggest that, when the liquid from a top layer reaches the upper boundary of its next (lower) layer, a localized accumulation of liquid on the top of the second fused layer occurs. In this case, an interesting phenomenon can be observed, consistent with results obtained in the cold model experiments, i.e. a fraction of the liquid flows towards the vertical left-side boundary of the second fused layer and then combines with the liquid source generated at this fused layer. At the same time, the remaining liquid flows along the top boundary of the second fused layer and forms an additional liquid source on the right-side boundary, leading to another liquid flow region. The former, appearing as a flow channel, significantly increases the nonuniform liquid distribution in the dropping zone and is an important contributor to increased gas pressure loss in the area. The latter must be considered in terms of the transition to unsoftened ore and the reduction in temperature, from the $\mathrm{CZ}$ to the lumpy zone in an actual blast furnace. Because of the liquid transfer between layers, liquid may accumulate and/or form a strong stream at the root of the CZ. To maintain a steady-state flow, liquid in the root is 


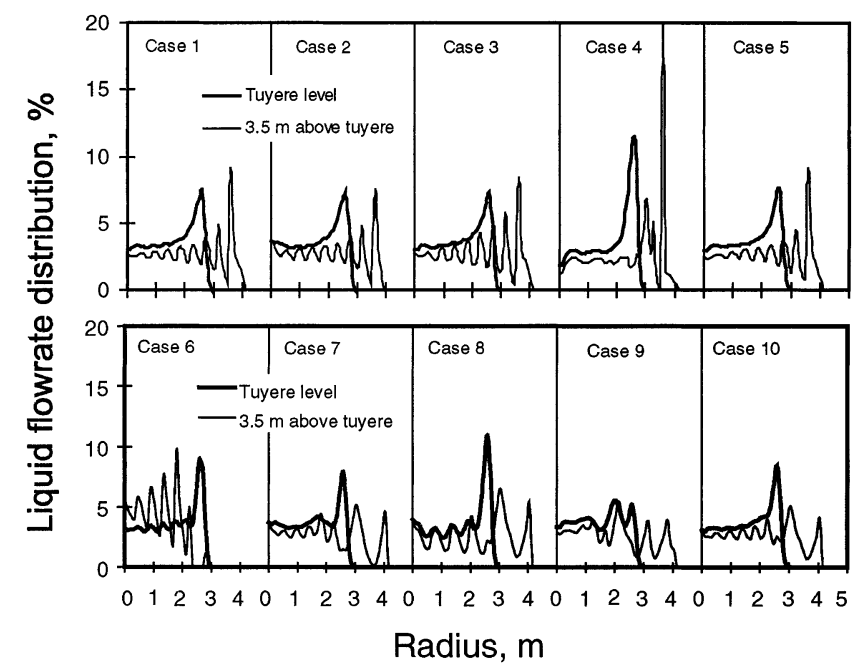

Fig. 11. Distribution of liquid flow rates on two specified crosssections.

forced to drop through the high gas flow region adjacent to a tuyere, giving a strong cross flow in front of the tuyere. This effect may be reduced in an actual three-dimensional blast furnace, as there is a significant region between tuyeres where liquid could drop with less gas interference. ${ }^{9)}$

The understanding of the gas and liquid flows in and below the $\mathrm{CZ}$ discussed above is of significance for the blast furnace with PCI operation. At high PCI rates, entry of unburnt char due to insufficient combustion of PCI coal in the raceway is inevitable. ${ }^{23-25)}$ The furnace operators need to understand the effect of the gas-liquid flow on the behavior of this residual char. ${ }^{26)}$ In this case, changes in permeability and stability in the blast furnace lower zone are a major concern. The movement and accumulation of liquid and char powder in this region are thought to play a major role in this change. The current model permits determination of the localized flow and accumulation of liquid, which provides a convenient way to predict the effect of this feature of liquid flow on the capture of char particles by coke bed in these localized regions. This effect will result in deterioration of the burden permeability in blast furnace, especially in the $\mathrm{CZ}$, and hence the furnace performance. Such interaction between liquid flow and char particles is still not yet considered in the existing blast furnace models. It is necessary to model this phenomenon for which current understanding is unfortunately insufficient. The discrete approach developed in the current work seems helpful in building such a practical gas-liquid-char flow model.

\subsection{Impacts of Structure $\mathbf{C Z}$}

The structure of a CZ changes with the operating conditions such as the furnace productivity and ore/coke ratio. Any unstable operation will also vary the $\mathrm{CZ}$. As indicated in Fig. 2, the structure of a CZ can be described by characteristic parameters. In order to investigate the influence of the $\mathrm{CZ}$ structure on liquid flow, the parameters were set as shown in Table 1, giving ten cases for the inverse V- and Wshaped CZs, respectively.

Figure 7 shows the changes of liquid flow pattern when changing the structural parameters under an inverse Vshaped CZ. Compared with the base condition shown in Fig. 5 (a), it can be seen that the distribution of liquid flow rates is significantly affected by the $\mathrm{CZ}$ structure. Decreasing the root height of the $\mathrm{CZ}$ (the root radius decreases accordingly) has a tendency to enlarge the flow region of liquid in the $\mathrm{CZ}$, especially in the $\mathrm{CZ}$ lower part. This implies that more liquid penetrates through the coke slits in the $\mathrm{CZ}$ due to the increased cross-flow of gas in this region, which may lead to deterioration of the burden permeability in the $\mathrm{CZ}$. Increasing the incline angle of the $\mathrm{CZ}$, $\beta$, has a similar effect as decreasing the $\mathrm{CZ}$ height, as shown in Fig. 7(c). Contrarily, decreasing the width and thickness of the $\mathrm{CZ}$ can improve the flow condition of gas through the $\mathrm{CZ}$ because of the decreased penetration depth of the liquid flow in coke slits and the relatively uniform liquid flow in the CZ, as indicated in Fig. 7(b) and 7(e). For these cases, the uniformity of liquid flow in the whole dropping zone is promoted to a certain extent. The liquid flow is probably most problematic as the number of the $\mathrm{CZ}$ layers increases. In this case, relatively high liquid flow rates arise in the regions nearby the $\mathrm{CZ}$ and in front of the raceway, especially in the root part of the CZ, as illustrated in Fig. 7(d).

The simulation shows that the structural changes of a Wshaped CZ have a similar influence on liquid flow in the blast furnace, as shown in Fig. 8. The liquid penetration through the coke slits in the $\mathrm{CZ}$ weakens under conditions such as decreasing the width of $\mathrm{CZ}$ layers, increasing the incline angle of the $\mathrm{CZ}, \beta$, and the thickness of the $\mathrm{CZ}$ layers. Decreasing the root height or root radius leads to an increased localized flow of liquid in the $\mathrm{CZ}$ (refer to Figs. $8(\mathrm{a})$ and $8(\mathrm{~d})$ ). On the other hand, it appears that increasing the number of CZ layers can improve the uniformity of liquid flow in the lower part of blast furnace to a certain extend. Comparing with the inverse $\mathrm{V}$-shaped $\mathrm{CZ}$, the difference is that the liquid-accumulated regions are enlarged, and are usually located on the top of the $\mathrm{CZ}$ layers. However these regions move toward the center of the blast furnace due to the shorter root radii, so that the liquid flow under this shape of $\mathrm{CZ}$ only offers a relatively weak effect on the flushing of the furnace wall.

Figures 9 and 10 show total holdup distribution of the liquid under conditions corresponding to Figs. 7 and 8, respectively. It can be seen that relatively high total liquid holdup occurs around the tuyere i.e. raceway or in the $\mathrm{CZ}$, in particular its root, which implies that these regions play a critical role in stabilizing the blast furnace. Such results are partly due to the strong localized flow of liquid, and partly due to liquid-liquid interaction in these regions. This simulation also shows the effect of the $\mathrm{CZ}$ structure, which corresponds to the flow patterns in various CZs as discussed above. For the inverse $\mathrm{V}$-shaped $\mathrm{CZ}$, reducing the height of $\mathrm{CZ}$ root enlarges the area with relatively high liquid holdup near the $\mathrm{CZ}$ and in the central blast furnace, as shown in Fig. 9. Decreasing the incline angle $\beta$ or the number of $\mathrm{CZ}$ layers results in an increased liquid holdup in the central blast furnace (refer to Figs. 6(a), 9(c) and 9(d)). Meanwhile increasing the thickness of coke slits exhibits an improved gas flow condition through the $\mathrm{CZ}$ because comparing Fig. 6(a) with Fig. 9(e) suggests that the width filled with relatively high liquid holdup near the $\mathrm{CZ}$ tends to reduce. For the $\mathrm{W}$-shaped $\mathrm{CZ}$, lower root of the $\mathrm{CZ}$ causes an increase in the liquid holdup in the center, "deadman" zone and $\mathrm{CZ}$ (refer to Figs. 6(b) and 10(a)). As illustrated in Fig. 10(d), 
the liquid holdup in the central blast furnace significantly increases as the root radius decreases (refer to Fig. 2). Changing the thickness of coke slits has an influence on the distribution of liquid holdup similar to that for the inverse V-shaped CZ.

Figure 11 indicates analyses on the flow rate distribution of liquid through two specified cross-sections for various cases, in term of the percentage of total liquid generation. One is at the tuyere level and another is at a height of $3.5 \mathrm{~m}$ above the tuyere. The results illustrate a gradually increased liquid flow rate along the radial direction, and exhibit a distribution peak in all cases in front of the raceway, or nearer the wall. The maximum flow rate at the tuyere level is formed by the blast pushing liquid away from the tuyere, and the maximum liquid flow rate above the tuyere is believed to be a combined contribution from the strong liquidliquid interaction and the drag of gas from the wall. The inverse V-shaped CZ exhibits a similar distribution of flow rates under various cases (see Cases 1 to 5). For the Wshaped $\mathrm{CZ}$, however, the distribution obviously changes with the position of the $\mathrm{CZ}$ root. For example, decreasing the $\mathrm{CZ}$ root radius (refer to Case 9) causes the disappearance of the distribution peak, and thus the liquid flow at the tuyere level is more uniform. This situation is due to the decreased liquid-liquid interaction. In addition, it can be found from Fig. 11 that, with the increase of the cross-section height from the tuyere level, the non-uniformity of the liquid flow increases. It is interesting that the liquid flow rate distribution is wavy rather than smooth. This is because the current model takes into account the fact that the liquid flow is discrete. As discussed before, the characteristics of the discrete liquid flow in a packed bed determine whether liquid-liquid interaction exists in a series of particular nodes in the given flow region. Wherever there is stronger liquid-liquid interaction those nodes will receive more liquid compared to other nodes, resulting in the discontinuous distribution of liquid flow rate.

It should be pointed out that the coke bed below the $\mathrm{CZ}$ in a blast furnace is not uniform, which will affect the permeability distribution and hence the gas and liquid flow. ${ }^{4}$ In fact, as demonstrated by Eto et al., ${ }^{14)}$ the non-uniform distribution of a packed bed affects the liquid flow pattern even without gas flow. Moreover, the liquid properties vary with temperature and hence are not constant, which will also affect the liquid flow, particularly in the lower part, including the deadman, where the rapid temperature change can be observed. ${ }^{3)}$ These factors were not considered in the present work focused on the effect of $\mathrm{CZ}$ characteristics.

Nonetheless, this study suggests that it is necessary to implement an accurate liquid flow model in blast furnace modelling. In fact, because of the horizontal, upward or even flooding flow around a $\mathrm{CZ}$, liquid holdup distribution in the $\mathrm{CZ}$ becomes a critical issue for the change to the permeability in the blast furnace. The current model places no limitations on liquid flow direction and can therefore predict any style of liquid flow occurring in a blast furnace. In the present work, the cases shown in Table 1 are relevant to furnace operation. For instance, the use of burden with favorable metallurgical properties can form a $\mathrm{CZ}$ with fused layers of small width; the number of $\mathrm{CZ}$ fused layers is related to the ore-to-coke ratio and burden distribution at the furnace top. Therefore it is possible to link the current model with the operating conditions of the blast furnace, providing a convenient way to monitor changes of burden permeability in blast furnace and provide guidance for achieving stable furnace operation.

\section{Conclusions}

A newly developed gas-liquid two-phase model has been employed to simulate the gas and liquid flow in a blast furnace with three typical CZs, i.e., inverse $\mathrm{V}-, \mathrm{V}$ - and $\mathrm{W}$ shaped. In this model, the fused ore layers in the $\mathrm{CZ}$ are treated as impermeable layers and the liquid generated from the fused layers is regarded as a discrete phase. The model predicts that the physical structure of the $\mathrm{CZ}$ has significant influence on the liquid flow. The major findings from the present simulations include:

(1) Existence of the impermeable CZ layers in the blast furnace is the most important factor that causes the localized liquid flow in the lower part of the blast furnace. Decreasing the root height or increasing the incline angle of the $\mathrm{CZ}$ will enlarge the flow region of liquid in the $\mathrm{CZ}$, strengthening the localized liquid flow both in the $\mathrm{CZ}$ lower part and in front of the raceway. Decreasing the width and thickness of the $\mathrm{CZ}$ gives a decreased penetration depth of liquid flow into coke slits and the relatively uniform liquid flow in the $\mathrm{CZ}$ and hence improve the flow condition of gas through the $\mathrm{CZ}$. The higher the number of $\mathrm{CZ}$ layers, the stronger the localized liquid flow in the $\mathrm{CZ}$, and hence the relatively high liquid holdup arises within the $\mathrm{CZ}$ in this case.

(2) There exists a strong interaction between gas and liquid flows in the blast furnace, resulting in the localized horizontal or upward liquid flow around the $\mathrm{CZ}$ and in front of the raceway.

(3) Also, there exists a strong interaction among liquid flows that are generated from different fused layers in the $\mathrm{CZ}$, which causes the obviously non-uniform liquid flow in and below the $\mathrm{CZ}$.

(4) Penetration and accumulation of liquid in coke slits in the $\mathrm{CZ}$ give an increased liquid holdup in this region, which suggests that the behavior of liquid flow in the $\mathrm{CZ}$ could be a dominant factor to control burden permeability, in particular, for PCI operation.

\section{Acknowledgments}

The financial support provided by ARC (Australian Research Council) and CRC (Cooperative Research Centre for Black Coal, Australian) is gratefully acknowledged.

\section{Nomenclature}

$a_{0}$ : Model parameter defined in Eq. (5) (-)

$A_{\mathrm{g}-1}, A_{\mathrm{s}-1}$ : The effective contact areas between liquid and gas, and liquid and solid, respectively $\left(\mathrm{m}^{2}\right)$

$C_{\mathrm{DG}}, C_{\mathrm{DS}}$ : The gas drag coefficient and bed drag coefficient, respectively $(-)$

$d_{\mathrm{P}}: \quad$ Diameter of packed particle $(\mathrm{m})$

$F_{i, j}:$ Flow rate of liquid passed by point $(i, j)\left(\mathrm{m}^{3} / \mathrm{h}\right)$

$\vec{F}_{j}^{i}$ : Interaction force of phase $i$ on phase $j(i, j=\mathrm{g}, 1$, or bed) $\left(\mathrm{N} / \mathrm{m}^{3}\right)$

$\vec{g}$ : Gravity $\left(\mathrm{m} / \mathrm{s}^{2}\right)$

$n_{\Sigma}:$ Number of CZ layers (-) 
$m_{0}$ : Total numbers of the initial liquid sources for a given CZ layer (-)

$p_{i, j, k}$ : Probability fraction of the discrete liquid flowing from the given point $(i, j)$ to its neighbouring node $k(k=1,2, \ldots, 8)(-)$

$P$ : $\quad$ Gas pressure $(\mathrm{Pa})$

$q_{m}^{i}$ : Flow rate of liquid at the $m$-th initial point of the $i$-th $\mathrm{CZ}$ layer $\left(\mathrm{m}^{3} / \mathrm{h}\right)$

$Q_{\mathrm{g}}$ : Gas flow rate entering a tuyere $\left(\mathrm{Nm}^{3} / \mathrm{h}\right)$

$Q_{\mathrm{s}}$ : Slag rate in terms of tonne per day $(\mathrm{t} / \mathrm{d})$

$Q_{\Sigma}$ : Total liquid flow rate formed by whole $\mathrm{CZ}$ $\left(\mathrm{m}^{3} / \mathrm{h}\right)$

$T$ : A variable defined in Eq. (5) to sum the numbers of initial liquid sources $(-)$

$\vec{V}_{\mathrm{g}}, \vec{V}_{1}$ : Interstitial velocity vectors of gas and liquid in packed beds, respectively, $(\mathrm{m} / \mathrm{s})$

Greek letters

$\alpha, \beta$ : Incline angles defined in Fig. 2 (deg)

$\varepsilon_{i}$ : Volume fractions of the $i$-th phase ( $i=$ gas, liquid and particles) in packed beds, respectively, $(-)$

$\eta$ : Productivity coefficient of blast furnace $\left(\mathrm{t} / \mathrm{m}^{3} \cdot \mathrm{d}\right)$

$\mu_{\mathrm{g}}, \mu_{1}$ : Viscosities of gas and liquid phases, respectively $(\mathrm{Pa} \cdot \mathrm{s})$

$\rho_{\mathrm{g}}, \rho_{1}$ : Densities of gas and liquid, respectively $\left(\mathrm{kg} / \mathrm{m}^{3}\right)$

$\phi_{1}, \phi_{2}$ : Model parameters defined by Eqs. (3c) and (3d), respectively $\left(\mathrm{m}^{-1}\right)$

$\psi$ : Particle shape factor $(-)$

\section{REFERENCES}

1) M. Horio: Transport Phenomena in the Lower Part of Blast Furnace, ISIJ, Tokyo, (1992), 68.

2) Y. Kajiwara and J. Szekely: Metall. Trans., 10B (1979), 447.

3) T. Sugiyama: Proc. Int. Conf. on Modelling and Simulation in Metallurgical Engineering and Materials Science, Metallurgical Industry Press, Beijing, (1996), 270.
4) Y. Omori: Blast Furnace Phenomena and Modelling, Elsevier Applied Science, London, (1987), 376.

5) J. Yagi: ISIJ Int., 33 (1993), 619.

6) P. R. Austin, H. Nogami and J. Yagi: ISIJ Int., 37 (1997), 458.

7) G. S. Gupta, J. D. Litster, V. R. Rudolph, E. T. White and A. Domanti, ISIJ Int., 36 (1996), 32.

8) G. S. Gupta, J. D. Litster, E. T. White and V. R. Rudolph: Metall. Trans., 28B ( 1997), 597.

9) S. J. Chew, G. X. Wang, A. B. Yu and P. Zulli: Ironmaking Steelmaking, 24 (1997), 392.

10) D. Y. Liu, S. Wijeratne and J. D. Litster: Scand. J. Metall., 26 (1997), 79.

11) D. Y. Liu, G. X. Wang, J. D. Litster and P. Zulli: ICSTI/Ironmaking Conf. Proc., ISS, Warrendale, PA, 57 (1998), 293.

12) Y. Ohno and K. Kondo: Trans. Iron Steel Inst. Jpn., 20 (1980), B495.

13) J. Wang, R. Kahashi and J. Yagi: Tetsu-to-Hagané, 77 (1991), 1585.

14) Y. Eto, K. Takeda, S. Miyagawa, S. Taguchi and H. Itaya: ISIJ Int., 33 (1993), 681.

15) G. X. Wang, S. J. Chew, A. B. Yu and P. Zulli: Metall. Trans., 28B (1997), 333.

16) G. X. Wang, S. J. Chew, A. B. Yu and P. Zulli: ISIJ Int., 37 (1997), 573.

17) J. M. Steiler, R. Nicolle, P. Negro, M. Helleisen, N. Jusseau, B. Metz and C. Thirion: Proc. Ironmaking Conf., ISS, Warrendale, PA, 50 (1991), 715

18) G. X. Wang, D. Y. Liu, J. D. Litster, S. J. Chew and P. Zulli: Chem. Eng. Sci., 52 (1997), 4013.

19) Y. Sawa, K. Takeda and S. Taguchi: Ironmaking Conf. Proc., ISS, Warrendale, PA, 50 (1991), 417.

20) M. Sasaki, K. Ono, A. Suzuki, Y. Okuno and K. Yoshizawa: Trans. Iron Steel Inst. Jpn., 17 (1977), 391.

21) W. H. Press, S. A. Teukosky, W. T. Vetterling and B. P. Flannery: Numerical Recipes in FORTRAN-the Art of Scientific Computing, 2nd Ed., Cambridge University Press, Cambridge, (1992), 413.

22) P. R. Austin: Modelling of liquid flow in the blast furnace shaft, Internal report-BHPR/MPR/TN/94/022, (1994).

23) K. H. Peters, H. Kowalsk, B. Korthas and K. Kreibish: Proc. Ironmaking Conf., ISS, Warrendale, PA, 48 (1989), 819.

24) K. Yamaguchi, H. Ueno, S. Matsunaga, K. Kakiuchi and S. Amano: ISIJ Int., 35 (1995), 148.

25) K. Takeda, S. Taguchi, T. Fukutake, H. Kato, N. Takashima and T. Nakai: Tetsu-to-Hagané, 72 (1986), S871.

26) D. Pinson, A. B. Yu, P. Zulli and M. J. McCarthy: Proc. Int. Conf. Oxygen-Coal Iron-Steel Making, ed. by W. D. Huang, Metallurgical Industry Press, Beijing, (1997), 396-407. 